\title{
Dosagem Sérica de Adenosina Deaminase em Lúpus Eritematoso Sistêmico: Ausência de Associação com Atividade de Doença ${ }^{(*)}$
}

\section{Levels of Serum Adenosine Deaminase in Systemic Lupus Erythematosus: Lack of Association with Disease Activity}

\author{
Isabella Lima $^{(1)}$, Fátima Néri( ${ }^{(2)}$, Mittermayer Barreto Santiago ${ }^{(3)}$
}

\section{RESUMO}

O lúpus eritematoso sistêmico (LES) é uma doença inflamatória auto-imune, que evolui intercalando períodos de atividade e remissão. Objetivo: avaliar a associação da dosagem sérica de adenosina deaminase (ADA) e atividade do LES, segundo os critérios do SLEDAI $2 \mathrm{~K}$ - Systemic lupus erythematosus disease activity index. Métodos: avaliou-se 82 pacientes com LES atendidos em um hospital de referência para o tratamento do LES em Salvador, BA, Brasil. A atividade de doença foi determinada pelo SLEDAI $2 \mathrm{~K}$ e a dosagem sérica da ADA realizada por colorimetria. Resultados: oitenta e uma pacientes $(98,78 \%)$ eram do sexo feminino e a idade média foi

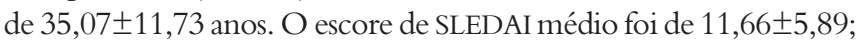

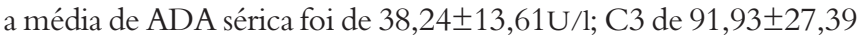
$\mathrm{mg} / \mathrm{dl} ; \mathrm{C} 4$ de $15,17 \pm 5,77 \mathrm{mg} / \mathrm{dl}$ e a pesquisa de anticorpos antiDNA nativo (aDNAn) foi positiva em 31 casos (37,8\%). Não houve correlação entre os níveis séricos de ADA e escore do SLEDAI. A ADA sérica correlacionou-se inversamente com $\mathrm{C} 4(\mathrm{r}=-0,336 \mathrm{e}$ $\mathrm{p}=0,001)$. Conclusões: no presente estudo a dosagem sérica de ADA não se associou a atividade de doença segundo os critérios do SLEDAI 2K, sugerindo que esse teste não deve ser utilizado como marcador de atividade de doença em LES. Esse resultado diverge da maioria dos trabalhos publicados, o que pode ser explicado pela dificuldade de padronização da técnica de dosagem da ADA ou por diferença nas diversas populações estudadas.

Palavras-chave: adenosina deaminase, lúpus eritematoso sistêmico, SLEDAI.

\begin{abstract}
Systemic lupus erythematosus (SLE) is an autoimmune inflammatory disease, with a variable course and characterized by periods of remissions and exacerbations. Objective: To evaluate the association between serum adenosine deaminase (ADA) levels and disease activity in SLE. Methods: Eighty two SLE patients seen at Santa Izabel Hospital in Salvador, BA, Brazil, were studied. Disease activity was measured by SLEDAI $2 K-$ Systemic Lupus Erythematosus Disease Activity Index, and serum ADA was detected by colorimetric assay. Results: Eighty one patients were female; mean age was $35.07 \pm 11.73$ years. The mean SLEDAI score was $11.66 \pm 5.89$; mean serum ADA was $38.24 \pm 13.61 \mathrm{U} / \mathrm{l}$; C3 level was $91.93 \pm 27.39 \mathrm{mg} / \mathrm{dl}$; C4 level was $15.17 \pm 5.77 \mathrm{mg} / \mathrm{dl}$ and anti-DNA antibodies were detected in $31(37.8 \%)$ patients. There was no correlation between serum ADA level and SLEDAI score. We found an inverse relationship between $C 4$ level and serum ADA. Conclusions: In the present study, we have not demonstrated a correlation between serum ADA and SLEDAI score, therefore it should not be used as a marker for disease activity in SLE. These findings are divergent from most of the previous studies. It could be explained by the difference in the studied populations or due to the lack of standardization of the ADA measurement technique.
\end{abstract}

Keywords: adenosine deaminase, systemic lupus erythematosus, SLEDAI.

\footnotetext{
Trabalho realizado no Núcleo de Reumatologia da Bahia, Escola Bahiana de Medicina e Saúde Pública (EBMSP), Salvador, BA, Brasil. Recebido em 05/0 1/2005. Aprovado, após revisão, em 02/10/2005

1. Reumatologista do Núcleo de Reumatologia da Bahia, EBMSP.

2. Oftalmologista do Hospital Santa Izabel, Salvador, BA, Brasil.

3. Professor adjunto doutor da EBMSP e Coordenador do Núcleo de Reumatologia da Bahia, EBMSP.

Endereço para correspondência: Dr. Mittermayer Santiago. Núcleo de Reumatologia da Bahia. Hospital Santa Izabel, Praça Almeida Couto, 500, CEP 40.000-000, Nazaré. Salvador, BA, Brasil. E-mail: mitter@svn.com.br
} 


\section{INTRODUÇÃO}

O lúpus eritematoso sistêmico (LES) é uma doença inflamatória crônica, de caráter auto-imune, que acomete predominantemente mulheres jovens.

Embora as causas do LES não sejam completamente conhecidas, sabe-se que a interação entre fatores genéticos, ambientais e hormonais promove uma disfunção no sistema imunológico, levando à hiperativação de linfócitos $\mathrm{T}$ e B, com produção de auto-anticorpos e formação de imunocomplexos mediadores das lesões teciduais.

A apresentação clínica é polimórfica, podendo levar ao acometimento de diversos órgãos e sistemas, evoluindo caracteristicamente em períodos intercalados de atividade e remissão. O reconhecimento da doença ativa é importante, pois implica decisões terapêuticas.

Quadros infecciosos são freqüentes em pacientes com LES, seja pela disfunção imunológica da própria doença, seja em decorrência da imunossupressão induzida pelo tratamento e, por si só, concorrem com morbimortalidade para estes pacientes. Além disso, as infecções simulam freqüentemente atividade de doença, causando dificuldades para reconhecer o status ativo do LES e dificultando a indicação do tratamento mais adequado.

A participação da adenosina deaminase (ADA) no sistema imunológico foi inicialmente sugerida pela verificação de imunodeficiência grave em portador da deficiência desta enzima $^{(1)}$. Posteriormente, demonstrou-se sua participação na maturação de monócitos ${ }^{(2)}$ e linfócitos ${ }^{(3,4)}$.

Reconhecendo a hiperativação de linfócitos $\mathrm{T}$ e B no contexto do lúpus, propusemo-nos a fazer a dosagem sérica da ADA nestes pacientes, para a verificação da associação de seus níveis com parâmetros de atividade de doença já estabelecidos.

\section{PACIENTES E MÉTODOS}

Realizou-se um estudo de coorte transversal, previamente aprovado pelo Comitê de Ética, no qual foram avaliados 82 pacientes portadores de LES, atendidos consecutivamente no Ambulatório de Colagenoses do Hospital Santa Izabel, Salvador, BA, Brasil, no período de agosto de 2003 a janeiro de 2004. Os critérios de inclusão foram: consentimento livre e esclarecido por parte dos pacientes e preenchimento dos critérios de classificação do American College of Rheumatology para $\operatorname{LES}^{(5,6)}$. O critério de exclusão foi presença de qualquer infecção, inclusive tuberculose e HIV.
Para o estabelecimento do escore do SLEDAI $2 \mathrm{~K}^{(7)}$, realizou-se questionário, exame físico, dosagem de C3, C4 e pesquisa de anticorpos anti-DNA nativo (aDNAn). Considerou-se apenas as alterações presentes no momento da avaliação ou até dez dias antes. A avaliação oftalmológica foi realizada em todos os pacientes também dentro desse prazo. As dosagens séricas de $\mathrm{C} 3$ e $\mathrm{C} 4$ foram realizadas por imunoturbinometria e os resultados expressos em $\mathrm{mg} / \mathrm{dl}$. Considerou-se valor de normalidade para C3: 70 a 176 $\mathrm{mg} / \mathrm{dl}$ e para C4: 12 a $36 \mathrm{mg} / \mathrm{dl}$. A pesquisa de aDNAn foi realizada por imunofluorescência indireta, utilizando o antígeno Crithidia luciliae. ADA sérica foi realizada em amostras de soros conservados a $70^{\circ} \mathrm{C}$ negativos logo após a coleta, o que garantiu a viabilidade da enzima. Utilizouse kit comercial Diazyme, método colorimétrico. O ensaio para dosagem de ADA baseia-se na desaminação da adenosina em inosina, a qual é convertida em hipoxantina por ação da purina nucleosídeo fosforilase (PNP). A hipoxantina, por sua vez, é convertida em ácido úrico e peróxido hidrogênio $\left(\mathrm{H}_{2} \mathrm{O}_{2}\right)$ pela xantina oxidase $(\mathrm{XO})$. $\mathrm{H}_{2} \mathrm{O}_{2}$ reage com N-etil-N(2-hidroxi-3-sulfopropil)-3-metilanilina (EHSPT) e com 4 amino antipirina (4-AA) na presença de peroxidase e gera corante quinona, a qual é quantificada por método colorimétrico.

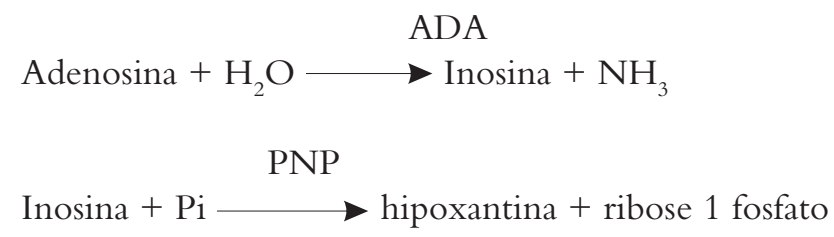

Hipoxantina $+2 \mathrm{H}_{2} \mathrm{O}+2 \mathrm{O}_{3} \longrightarrow$ ácido úrico $+2 \mathrm{H}_{2} \mathrm{O}_{2}$
$2 \mathrm{H}_{2} \mathrm{O}_{2}+4-\mathrm{AA}+\mathrm{EHSPT} \stackrel{\mathrm{PO}}{\longrightarrow} 4 \mathrm{H}_{2} \mathrm{O}+$ quinona

Uma unidade de ADA é definida como a quantidade de ADA necessária para gerar $1 \mu \mathrm{mol}$ de inosina por minuto à $37^{\circ} \mathrm{C}$.

As variáveis nominais foram descritas sob a forma de freqüências e as variáveis intervalares sob a forma de média \pm desvio padrão acrescido da mediana e dos valores máximo e mínimo quando esta não tinha distribuição normal.

Foi testada a normalidade de distribuição das variáveis intervalares pelo Teste de Kolmogorov Smirnov, além da análise de média, mediana, moda, da simetria e do achatamento da curva e histograma. Transformação logarítmica 
foi usada para corrigir desvios de normalidade para análise estatística quando indicado. As diferenças na distribuição da ADA segundo sinais e sintomas ou alterações laboratoriais foram analisadas por meio do Teste de Mann-Whitney. A associação entre as variáveis foi medida pelo Coeficiente de Spearman.

\section{RESULTADOS}

Foram estudados 82 pacientes, dos quais 81 (98,7\%) eram do sexo feminino. Em função da prevalência quase absoluta deste sexo, esta variável não foi considerada na análise estatística.

Quanto à raça, 25 (30,5\%) eram caucasianos, 23 (28\%) afrobrasileiros e 34 (41,5\%) mulatos. Tinham idade média de $35,0 \pm 11,7$ anos, tendo variado de 13 a 62 e o tempo de doença era de 2 a 384 meses, com média em 78,2 $\pm 76,1$ meses.

Do ponto de vista clínico, os sinais e sintomas presentes por ocasião da avaliação ou até dez dias antes estão sumarizados na Tabela 1 e do ponto de vista laboratorial, as alterações presentes também relativas à avaliação ou até dez dias antes estão relacionadas na Tabela 2.

Dos 82 pacientes estudados, 35 (42,7\%) vinham em uso de cloroquina; 2 (2,4\%) em uso de metotrexato (dose média de $11,25 \mathrm{mg} /$ semana); 15 (18,3\%) em uso de azatioprina (dose média de 101,66mg/dia); 7 (8,5\%) em uso de ciclofosfamida em pulsoterapias mensais de $1 \mathrm{~g} ; 2$ (2,4\%) em uso de talidomida (50mg/dia) e $45(56,1 \%)$ em uso de prednisona (dose média de 12,33mg/dia).

A dosagem sérica da ADA realizada nos pacientes obteve valor médio de $38,2 \pm 13,6 \mathrm{U} / 1$, mediana 35,7 , tendo variado de 14,7 a $78,2 \mathrm{U} / 1$.

TABELA 1

FREQÜÊNCIA DE SINAIS E SINTOMAS PRESENTES NA AVALIAÇÃO OU ATÉ DEZ DIAS ANTES NA AMOSTRA ESTUDADA

\begin{tabular}{lc}
\hline Sinais e sintomas & $\mathbf{N}(\%)$ \\
\hline Febre & $24(29,3 \%)$ \\
\hline Alopecia & $70(85,4 \%)$ \\
Rash & $46(56,1 \%)$ \\
Lesões de mucosa & $25(30,5 \%)$ \\
Artrite & $44(53,7 \%)$ \\
Pleurite & $3(3,7 \%)$ \\
Pericardite & $1(1,2 \%)$ \\
Glomerulonefrite & $23(28,0 \%)$ \\
Vasculite & $7(8,5 \%)$ \\
Psicose & $1(1,2 \%)$ \\
\hline
\end{tabular}

TABELA 2

FREQÜÊNCIA DAS ALTERAÇÕES LABORATORIAIS PRESENTES NA AVALIAÇ̃̃O OU ATÉ DEZ DIAS ANTES NA AMOSTRA ESTUDADA

\begin{tabular}{lc}
\hline Alterações laboratoriais & $\mathbf{N}(\%)$ \\
\hline Leucopenia* & $44(53,7 \%)$ \\
\hline Plaquetopenia\# & $12(14,6 \%)$ \\
\hline Anemia hemolítica+ & $14(17,0 \%)$ \\
\hline Proteinúria** & $22(26,8 \%)$ \\
\hline Hematúria & $15(18,3 \%)$ \\
\hline Cilindrúria & $14(17,1 \%)$ \\
\hline Leucocitúria & $6(7,3 \%)$ \\
\hline Anti-DNA nativo & $31(37,8 \%)$ \\
\hline Diminuição de C3 & $18(22,0 \%)$ \\
\hline Diminuição de C4 & $30(36,5 \%)$ \\
\hline
\end{tabular}

* contagem de leucócitos menor que $3000 / \mathrm{mm}^{3}$; \# contagem de plaquetas menor que $100.000 / \mathrm{mm}^{3} ;$ + hemoglobina $<11 \mathrm{mg} / \mathrm{dl}$, teste de Coombs direto positivo e reticulocitose; ** proteinúria maior que $500 \mathrm{mg} / 24$ horas

ADA sérica não apresentou distribuição normal. Comparou-se a mediana de ADA entre grupos sintomáticos e assintomáticos para cada sintoma isoladamente (Tabela 3); para as alterações laboratoriais presentes ou ausentes (Tabela 4); assim como de acordo com o uso de medicações.

A mediana de ADA foi significativamente menor nos pacientes plaquetopênicos $(\mathrm{p}<0,012)$ comparando-se aos indivíduos com contagem de plaquetas normais.

TABELA 3

COMPARAÇÃO DAS MEDIANAS DE ADA NOS DIFERENTES SINAIS E SINTOMAS

\begin{tabular}{lcccc}
\hline & $\mathbf{n}$ & Mediana & Mín./máx. & $\mathbf{P}$ \\
\hline Febre & +24 & 33,3 & $14,7 / 61,6$ & 0,059 \\
& -58 & 38,7 & $15,9 / 78,2$ & \\
Alopecia & +70 & 35,7 & $15,9 / 78,2$ & 0,508 \\
& -12 & 37,75 & $14,7 / 70$ & \\
Rash malar & +46 & 38,4 & $20,6 / 78,2$ & 0,260 \\
& -36 & 34 & $14,7 / 61,6$ & \\
Lesão mucosa & +25 & 36,1 & $19 / 70$ & 0,700 \\
& -57 & 35,3 & $14,7 / 78,2$ & \\
Artrite & +44 & 34,4 & $14,7 / 70$ & 0,130 \\
& -38 & 37,1 & $19 / 78,2$ & \\
Pleurite & +3 & 37,7 & $14,7 / 46,6$ & 0,670 \\
& -79 & 35,3 & $15,9 / 78,2$ & \\
Vasculite & +7 & 31,9 & $20,6 / 40,2$ & 0,170 \\
& -75 & 37,7 & $14,7 / 78,2$ & \\
Psicose & +1 & 25 & $25 / 25$ & 0,310 \\
& -81 & 36,1 & $14,7 / 78,2$ & \\
\hline
\end{tabular}

+ presente; - ausente 
TABELA 4

Comparação das MEdianas de ADA de ACORdo COM AS ALTERACÕES LABORATORIAIS

\begin{tabular}{lcccc}
\hline & $\mathbf{n}$ & Mediana & Mín./máx. & $\mathbf{P}$ \\
\hline Leucopenia & +44 & 34,9 & $14,7 / 70$ & 0,570 \\
& -38 & 36,9 & $15,9 / 78,2$ & \\
Plaquetopenia & +12 & 27,5 & $20,6 / 45,6$ & $\mathbf{0 , 0 1 2 *}$ \\
& -70 & 37,8 & $14,7 / 78,2$ & \\
Anemia hemolítica & +14 & 25,5 & $14,7 / 70$ & 0,470 \\
Proteinúria & -68 & 36,2 & $16,2 / 78,2$ & \\
& +22 & 39,45 & $14,7 / 61,6$ & 0,280 \\
Hematúria & -60 & 33,4 & $15,9 / 78,2$ & \\
Cilindrúria & +15 & 37,7 & $14,7 / 59,3$ & 0,230 \\
& -67 & 33,5 & $15,9 / 78,2$ & \\
\hline Leucocitúria & +14 & 35,5 & $14,7 / 61,6$ & 0,550 \\
& -68 & 35,7 & $15,9 / 78,2$ & \\
\hline
\end{tabular}

+ presente; - ausente; * Mann-Whitney, significância $p<0,05$

O SLEDAI 2K, utilizado como instrumento para avaliação de atividade de doença, alcançou um escore médio de $11,6 \pm 5,8$ e escore mínimo e máximo de 2 e 30 .
Detalhamos ainda os achados em relação à C3, C4 e aDNAn, exames laboratoriais estes sabidamente correlacionados com atividade de doença. O nível médio de C3 foi de $91,9 \pm 27,3 \mathrm{mg} / \mathrm{dl}$ e o de C4 de $15,7 \pm 5,7 \mathrm{mg} / \mathrm{dl}$, sendo que C3 e C4 estavam abaixo da normalidade, em 18 $(21,9 \%)$ e $30(36,5 \%)$ pacientes, respectivamente.

A pesquisa dos anticorpos aDNAn, com resultados em títulos de diluição, teve média geométrica zero, tendo sido positivo em 31 (37,8\%) pacientes.

A distribuição da variável dosagem sérica de ADA era anormal, sendo feita uma transformação logarítmica com normalização de sua distribuição. A dosagem de aDNAn em função de seu resultado fornecido em títulos de diluição também foi analisada em sua transformação logarítmica.

Log ADA correlacionou-se inversamente com C4 ( $\mathrm{r}-0,336$ e $\mathrm{p}<0,010)$ (Figura 1). Não houve significância na correlação com C3 $(p=0,080)$, escore de SLEDAI $(p=0,069)$ (Figura 2) e log de aDNAn $(p=0,182)$.

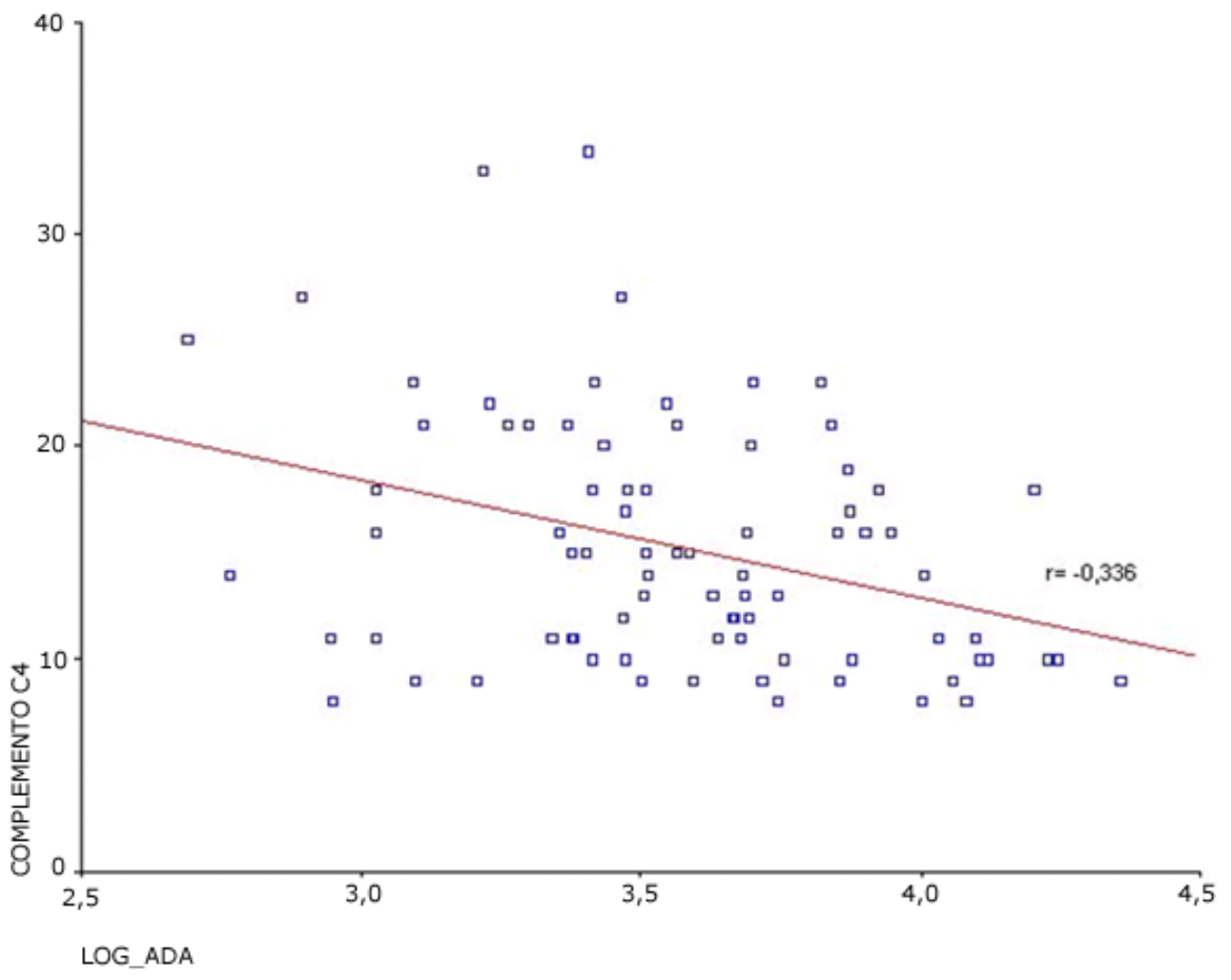

FIGURA 1 - Distribuição da correlação entre C4 e log ADA 


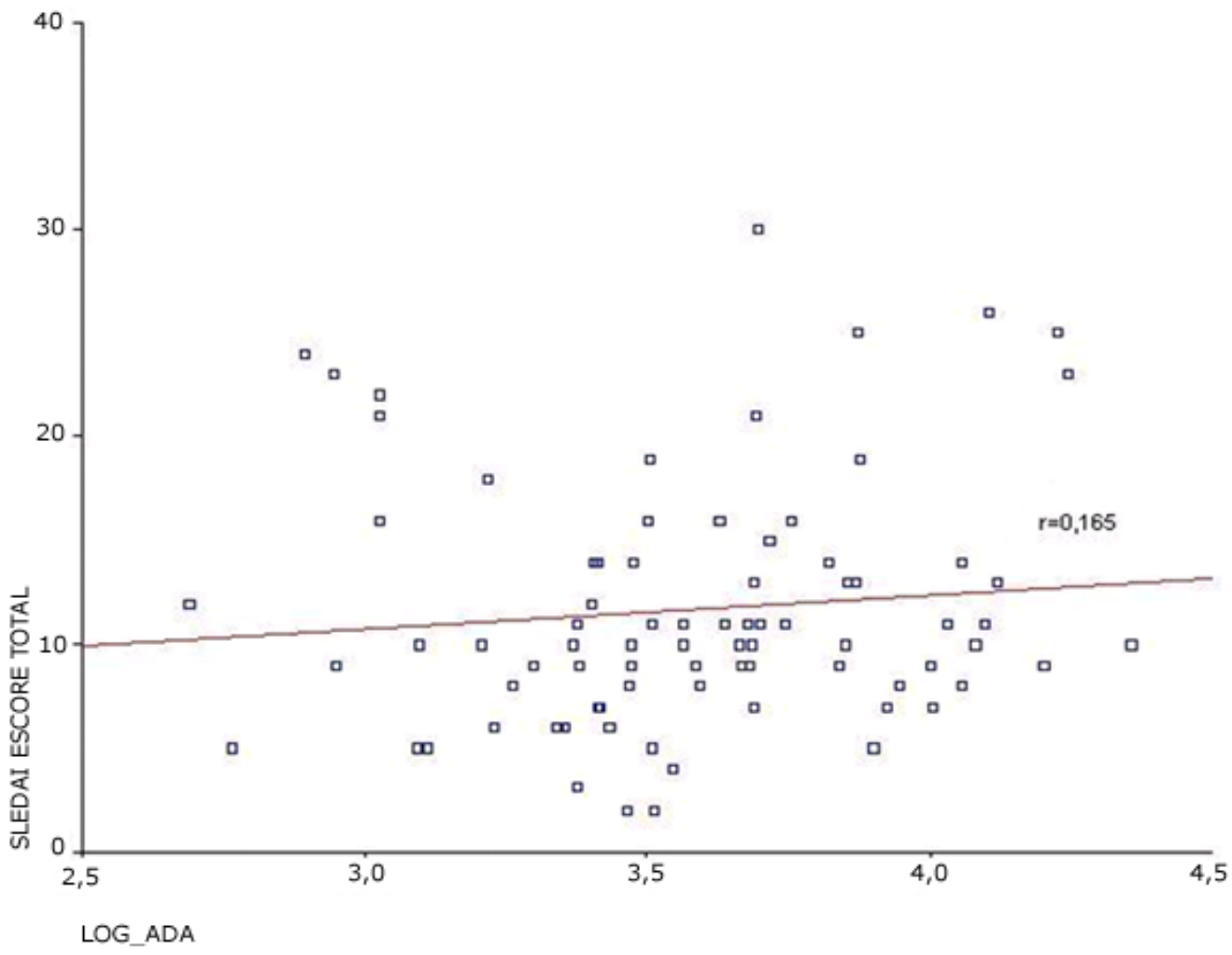

FIgURA 2 - Distribuição da correlação das variáveis SLEDAI e log ADA

\section{DISCUSSÃo}

Sendo o LES uma doença que se caracteriza por períodos de exacerbação e acalmia e ao mesmo tempo sendo uma condição que predispõe ao aparecimento de infecção, que por si só pode mimetizar uma atividade de doença, tornase muito importante a procura de parâmetros que permitam definir com segurança a existência de atividade, uma vez que a estratégia terapêutica pode mudar completamente.

A capacidade de avaliação da dosagem sérica de ADA como marcador de atividade de doença em LES está relacionada com o conhecimento desta condição como característica imunológica marcante para a ativação de linfócitos CD4, importantes produtores de ADA. No sentido de estudar o papel da dosagem sérica de ADA como marcador de atividade, optou-se pela comparação dos seus níveis com o escore do SLEDAI 2K, que é um instrumento validado mundialmente da atividade de doença e utiliza diferentes parâmetros clínicos e laboratoriais para sua definição. Sabese que o escore de SLEDAI pode assumir valores de 0 a 105, mas os próprios autores verificaram, durante sua vali- dação, que, raramente, atinge um valor maior ou igual a $45^{(8)}$. Infelizmente não há critérios previamente estabelecidos do que é considerado atividade, recorrência ou remissão. Observa-se que cada trabalho estabelece o ponto de corte para a atividade no SLEDAI. Em razão disso, e também porque não se conhece um cut off acima do qual ADA sérica é considerada positiva, enfatizou-se no presente trabalho a análise da correlação entre essas duas variáveis.

Como ADA pode estar aumentada em determinadas infecções, optou-se por estudar apenas pacientes vistos em ambulatório, uma vez que pacientes com LES freqüentemente são internados por causas infecciosas, o que poderia dificultar a interpretação da dosagem sérica de ADA. Por outro lado, evitando-se estudar pacientes internados, perde-se a oportunidade de estudar aqueles em atividade de doença como nefrite, artrite, e envolvimento do sistema nervoso central, responsáveis por boa parte das internações hospitalares.

O predomínio de pacientes do sexo feminino observado neste estudo vem concordar com os dados epidemiológicos acerca de maior incidência do LES em mulheres, embora saibamos que a proporção descrita é em torno de 10:1 ${ }^{(9)}$. 
Inicialmente comparou-se a mediana de ADA entre dois grupos independentes: sintomáticos e assintomáticos para cada sintoma isoladamente. Não há na literatura descrições da relação da pericardite lúpica e ADA, entretanto, há de se notar que o único paciente do grupo que manifestava pericardite apresentou níveis de ADA menores que os demais. Os estudos publicados sobre ADA e pericardite relacionam-se principalmente ao valor da ADA para predizer a etiologia tuberculosa do derrame pericárdico e os resultados são controversos: um estudo envolvendo 108 pacientes com pericardite de etiologias diversas, dos quais 20 eram secundários a TB, a ADA do líquido pericárdico foi capaz de discriminar o derrame de etiologia tuberculosa dos demais com sensibilidade de $100 \%$ e especificidade de 91\%. Foi ainda observado valor prognóstico da ADA em predizer evolução para tamponamento ${ }^{(10)}$. Ao contrário, em outro estudo ${ }^{(11)}$, envolvendo 40 pacientes com derrame pericárdico, encontrou-se alta sensibilidade (97\%) na dosagem de ADA no líquido pericárdico para excluir o diagnóstico etiológico de TB, mas não para confirmá-lo. Dogan et al., em 1999(12) dosaram concomitantemente ADA sérica e em líquido pericárdico de 48 pacientes (24 com pericardite tuberculosa) e encontraram valor significativo da ADA dosada no líquido pericárdico para o diagnóstico de TB. No entanto, não houve associação da atividade de ADA sérica com aquela do líquido pericárdico. Em se tratando de apenas um paciente com pericardite no presente estudo, não podemos fazer inferências a esse respeito.

Estratificando-se os pacientes de acordo com as medicações que vinham sendo utilizadas, interessantemente, encontrou-se mediana de ADA em níveis elevados em dois pacientes que usavam talidomida. Não há dados na literatura sobre o papel da talidomida no metabolismo da ADA. Adicionalmente, não se pode tirar qualquer conclusão a esse respeito com a observação de apenas dois pacientes.

Não houve diferença estatística entre usuários e não usuários das demais medicações. Hosek et al., em 1991 ${ }^{(13)}$, observaram alterações de ADA a partir da administração de ciclofosfamida em ratos: houve diminuição da ADA, com exceção da atividade da enzima no baço, nos primeiros dias após o uso de ciclofosfamida, com elevação da ADA no período de recuperação após a droga. Em nossa amostra, havia sete pacientes em uso de ciclofosfamida, que não apresentaram alteração da ADA em relação aos demais. Entretanto, não se pode tirar conclusões definitivas pelo fato de não termos levado em consideração o tempo de uso da ciclofosfamida em relação a dosagem de ADA .
Cronstein et al., em 1994(14), demonstraram que um dos mecanismos antiinflamatórios do metotrexato (MTX) é mediado pela adenosina; mecanismo este, revertido especificamente pela ação da ADA e anti-receptor de adenosina 2, sugerindo interações do MTX e ADA. Ede et al., em $2002^{(15)}$, estudaram o metabolismo das purinas em 103 pacientes com AR antes e durante o uso de MTX. Especificamente em relação à ADA, observou-se diminuição significativa da ADA durante o tratamento com o MTX, mas esta diminuição não se associou à eficácia antiinflamatória ou hepatotoxicidade pelo MTX. Na amostra estudada, apenas dois pacientes vinham em uso de MTX e não se observou alterações da atividade da ADA nestes pacientes.

Por fim, buscamos a associação da ADA com os padrões de atividade classicamente conhecidos SLEDAI $2 \mathrm{~K}^{(6)}$, frações de complemento C3 e C4 e anticorpos aDNAn ${ }^{(16)}$. Observou-se que não houve correlação entre a dosagem sérica de ADA e o escore do SLEDAI, parecendo indicar que esse teste laboratorial não deve ser utilizado para o fim de avaliar atividade de doença em LES. Por outro lado, por meio da Correlação de Spearman identificamos uma correlação inversa entre os níveis séricos de ADA e C4 ( $\mathrm{r}=-0,336$ e $\mathrm{p}=0,001)$, parâmetro esperado quando em atividade de doença. No entanto, não podemos afastar a possibilidade dos baixos níveis de C4 serem decorrentes de outra causa, como, por exemplo, um defeito genético, às vezes observado em LES. A ausência de correlação entre os níveis de ADA com aqueles de C3 e de anticorpos aDNAn, que são outros marcadores de atividade, reforçam essa hipótese.

Poucos estudos foram publicados previamente sobre a atividade da ADA nos pacientes reumatológicos. Stoech et al., em 1981(17), em um estudo que envolveu portadores de doenças hematológicas e reumatológicas, à semelhança de nossos achados, não detectaram correlação entre os níveis séricos de ADA nos oito pacientes portadores de LES e atividade de doença. No entanto, outros autores demonstraram a associação da ADA e atividade de doença. Stancíková et al., em 1998 ${ }^{(18)}$, estudaram a associação entre ADA sérica e suas isoenzimas, e atividade de doença em 73 pacientes com LES. O instrumento de avaliação de atividade utilizado foi o ECLAM - European Consensus Lupus Activity Measure. Observaram um aumento significativo de ADA (subtipo 2) em relação aos controles saudáveis, além de uma forte correlação com o ECLAM (Spearman $\mathrm{r}=0,74$ e $\mathrm{p}<0,0001$; regressão linear $\mathrm{r}=0,68$ e $\mathrm{p}<0,01)$. Taisy et al., em $2002^{(19)}$, fizeram estudo semelhante, porém com menor número de pacientes ${ }^{(24)}$, no qual fez-se a do- 
sagem de ADA total, subtipos 1 e 2, além de citidina deaminase. Utilizou-se o SLEDAI para avaliar atividade de doença. Encontraram níveis de ADA total e ADA2 maiores dos que os controles, além de correlação positiva com SLEDAI (Pearson $\mathrm{r}=0,70$ e $\mathrm{p}<0,001$ ). Hitoglou et al., em $2001^{(20)}$, estudaram 24 pacientes com artrite idiopática juvenil (AIJ) e 10 portadores de LES, para os quais foram feitas as dosagens de ADA total e suas isoenzimas em linfócitos e no soro. Observaram aumento de ADA total e ADA2 séricas e aumento de ADA1 em linfócitos de todos os pacientes em relação a controles saudáveis. Foi significativa a correlação destes aumentos com critérios de atividade: SLEDAI para LES e número de articulações acometidas, VHS e PCR para AIJ.

Não realizamos neste estudo a dosagem das isoenzimas da ADA. Stancíková et al., em 1998, Taisy et al., em 2002, e Hitoglou et al., em 2001, demonstraram não só o aumento da ADA total como da isoenzima ADA 2 em pacientes com doença ativa. Embora não tenhamos encontrado associação

\section{REFERÊNCIAS}

1. Dissing J, Knudsen B: Adenosine deaminase deficiency and combined immunodeficiency syndrome. Lancet 2: 1316, 1972.

2. Fischer D, Weyden MBVD, Snyderman R, Kelley WN: A role for adenosine deaminase in human monocyte maturation. J Clin Invest 58: 399-407, 1976

3. Hovi T, Smyth JF, Allison AC, Willians SC: Role of adenosine deaminase in lymphocyte proliferation. Clin Exp Immunol 23: 395 403, 1976.

4. Shore AH, Dosch NH, Gelfand EW: Role of adenosine deaminase in the early stages of precursor $\mathrm{T}$ cell maturation. Clin Exp Immunol 44: 152-5, 1981.

5. Tan EM, Cohen AS, Fries JF, et al: The 1982 revised criteria for the classification of systemic lupus erythematosus. Arthritis Rheum 25: 1271-7.

6. Hochberg MC: Updating the american college of rheumatology revised criteria for the classification of systemic lupus erythematosus (letter). Arthritis Rheum 40: 1725, 1997.

7. Gladmann DD, Ibañez D, Urowitz MB: Systemic lupus erythematosus disease activity index 2000. J Rheumatol 29: 288-91, 2002.

8. Bombardier C, Gladman DD, Urowitz MB, Caron D, Chang $\mathrm{CH}$ and the Committee on Prognosis Studies in SLE. Derivation of the SLEDAI - a disease activity index for lupus patients. Arthritis Rheum 35: 630-40, 1992.

9. Gladmann DD, Urowitz MB: Systemic Lupus Erythematosus Clinical Features. In: Klippel JH, Dieppe PA. Rheumatology 2. ed. London: Mosby, V.2, section 7, cap 1, p.1.1-1.118, 1998.

10. Komsuoglu B, Goldeli O, Kulan K, Komsuoglu SS: The diagnostic and prognosis value of adenosine deaminase in tuberculous pericarditis. Eur Heart J 16: 1126-30, 1995.

11. Fijalkowska A, Szturmowicz M, Tomkowski W, et al: The value of measuring adenosine deaminase activity in pericardial effusion fluid do SLEDAI com ADA total, iniciamos em nosso serviço estudo para dosagem de isoenzimas da ADA.

Em conclusão, no presente estudo a dosagem sérica de ADA não se associou à atividade de doença segundo os critérios do SLEDAI 2K, sugerindo que esse teste não deve ser utilizado como marcador de atividade de doença em LES. Esse resultado diverge da maioria dos trabalhos publicados ${ }^{(18,19,20)}$, o que pode ser explicado pela diferença nas diversas populações estudadas ou pela falta de padronização da técnica de dosagem sérica da ADA. Existem vários kits comercializados para a dosagem desta enzima, os quais não são detalhados nos trabalhos publicados, o que pode dificultar a comparação dos resultados entre os mesmos.

\section{AGRADECIMENTOS}

Agradecemos ao Professor Edgar Marcelino o armazenamento dos soros a $-70^{\circ}$ no Serviço de Imunologia da Faculdade de Medicina da Universidade Federal da Bahia.

for diagnosing te etiology of pericardial effusion. Pneumonol Alergol Pol 2: 174-9, 1996.

12. Dogan R, Dermicin M, Sarigul A, Ciliv G, Bozer AY: Diagnostic value of adenosine deaminase activity in pericardial fluids. J Cardiovasc Surg 40: 501-4, 1999.

13. Hosec B, Bohacek J, Sikulova J: The effect os cyclophosphamide and gamma irradiation on adenosine deaminase and purine nucleoside phosphorylase in mice. Life Sci 49: 1403-7, 1991.

14. Cronstein BN, Naime D, Ostad E: The antiinflamatory effects of methotrexate are mediated by adenosine. Adv Exp Med Biol 370: 411-6, 1994

15. Ede AEV, Laan RF, Abreu RAD, Stegeman AB, Putte LBVD: Purine enzymes in patients with rheumatoid arthritis treated with methotrexate. Ann Rheum Dis 61: 1060-4, 2002.

16. Davis P, Cumming RH, Verrier-Jones J: Relationship between antiDNA antibodies, complement consumption and circulating immune complexes in Systemic lupus erythematous. Clin Exp Immunol 28:226-32, 1977.

17. Storch $\mathrm{H}$, Wilfried K, Rotzsch W: Adenosine deaminase acitivity in plasma and blood cells of patients with haematological and autoimmune diseases. Acta Haematol 65: 183-8, 1981.

18. Stancíkova M, Lukác J, Istok R, Cristalli G, Rovensky J: Serum adenosine deaminase activity and its isoenzyme pattern in patients with systemic lupus erythematosus. Clin Exp Rheumatol 16: 583-6, 1998.

19. Taisy S, Polat MF, Sari RA, Bakan E: Serum adenosine deaminase and cytidine deaminase activities in patients with systemic lupus erythematosus. Clin Chem Lab Med 40: 493-5, 2002.

20. Hitoglou S, Hatzistilianou M, Gougoustamou D, Athanassiadou F, Kotsis A, Catriu D: Adenosine deaminase activity and its isoenzyme pattern in patients with juvenile rheumatoid arthritis and systemic lupus erythematosus. Clin Rheumatol 20: 411-6, 2001. 